\title{
Parenting Similarity and Children with Attention-Deficit/Hyperactivity Disorder
}

\author{
Elizabeth A. Harvey
}

\begin{abstract}
This study examined the relation between parenting similarity and comorbid internalizing and disruptive behavior problems among 70 children with Attention-Deficit/Hyperactivity Disorder (ADHD). General child rearing similarity and discipline similarity were found to be associated with fewer disruptive behavior problems but not related to internalizing problems. Parenting similarity was also found to be associated with greater marital adjustment and less marital conflict among parents of ADHD children. In contrast to previous studies in non-clinical populations, controlling for parental effectiveness these relations are significant. Parenting similarity, related to fathers' reports of parenting alliance and discipline similarity, is also found to be associated with lower parenting stress for mothers. Implications for parent training for ADHD children are discussed. [Article copies available for a fee from The Haworth Document Delivery Service: 1-800-342-9678. E-mail address: getinfo@haworthpressinc.com <Website: http://www.haworthpressinc. com>]
\end{abstract}

KEYWORDS. Parenting, ADHD, family functioning, school-aged children

Children with Attention-Deficit/Hyperactivity Disorder (ADHD) display developmentally inappropriate levels of inattention, impulsiv-

Address correspondence to Elizabeth A. Harvey, Department of Psychology, University of Massachusetts, Tobin Hall, Box 37710, Amherst, MA 01003-7710.

The author thanks Russell Barkley and Gwenyth Edwards at the University of Massachusetts Medical Center for facilitating participant recruitment and data collection for this study.

Child \& Family Behavior Therapy, Vol. 22(3) 2000

(C) 2000 by The Haworth Press, Inc. All rights reserved. 
ity, and hyperactivity (American Psychiatric Association, 1994). They tend to exhibit higher than average rates of non-compliance (Cunningham \& Barkley, 1979; Mash \& Johnston, 1982) and are at risk of developing comorbid disruptive behavior problems (Barkley, DuPaul, \& McMurray, 1990) and internalizing problems (Breen \& Barkley, 1983). Research suggesting that the development of comorbid problems is a poor prognostic indicator for ADHD children (Barkley, 1990) points to the importance of understanding why some children develop comorbid difficulties and others do not.

One factor that may be contribute to the development of comorbid problems among ADHD children is interparental similarities in parenting values, beliefs, and practices. This construct, also called parental agreement or consistency, has been associated with fewer behavior problems among children (Block, Block, \& Morrison, 1981); however, the effects of parenting similarity have not yet been examined among families with ADHD children. Theory suggests that this variable might be particularly important among these families. First, ADHD children may be less forgiving of inconsistencies between mothers' and fathers' parenting. Second, it is thought that ADHD children have difficulties with self-regulation and are more dependent upon external feedback to regulate their behavior than normal children (Barkley, 1997). Thus the consistency of the external feedback provided by parents of ADHD children may be important determinants of the development of comorbid problems among these children. Third, compared to non-ADHD children, ADHD children present their parents with more frequent and more difficult problems (e.g., Johnston, 1996). When these problems are frequent and stressful, parental differences in handling childrearing problems may lead to difficulties in the marital relationship; strained marital relationships, in turn, may negatively affect ADHD children. Fourth, the elevated levels of stress that most parents of ADHD children experience (e.g., Breen \& Barkley, 1988; Mash \& Johnston, 1983) may impair parents' abilities to negotiate effectively and resolve parenting differences. Thus, parenting differences may be more likely to lead to marital conflict among parents of ADHD children, which, in turn, may negatively affect ADHD children. Thus, theory also suggests several ways in which the characteristics of ADHD may act as a catalyst, strengthening effects of parenting dissimilarity on the development of comorbid internalizing 
and disruptive behavior problems as well as on family functioning in general.

Although parenting similarity has been associated with fewer behavior problems in children (Block, Block, \& Morrison, 1981), more recent studies in nonclinical samples have suggested that parenting similarity is confounded with parenting quality and that apparent effects of parenting similarity might actually be due to the fact that good parents tend to have similar parenting views. Deal, Halverson, and Wampler (1989) found that, although parental agreement was associated with better family functioning, it rarely predicted family functioning when parenting effectiveness was controlled. Similarly, Sherrill (1995) reported that indices of interparental inconsistencies in childrearing views and in use of discipline strategies did not uniquely predict children's behavior problems, controlling for the quality of parenting.

The present study examined the relation between parenting similarity and ADHD children's comorbid internalizing and disruptive behavior problems. Given findings by Deal et al. (1989) and Sherrill (1995) that parenting similarity did not uniquely predict child characteristics, the effect of similarity was tested controlling for parenting quality. Because discipline practices are thought to have important consequences for these children (for review, see Kendziora \& O'Leary, 1993), this study focused both on general child rearing similarity and on similarity in discipline practices. To explore some possible processes by which parenting similarity might affect ADHD children, this study also examined the relations between parenting similarity and two important areas of family functioning: marital functioning and parenting well-being.

Three aspects of marital functioning were examined: marital conflict, parental alliance, and general marital adjustment. Minuchin's (1985) theory suggests that dissimilarity in child rearing may lead to greater marital conflict and parenting dissimilarity has been associated with greater family conflict (Block, Block, and Morrison, 1981); however, Deal et al. (1989) found no relation between parenting similarity and marital conflict when parenting effectiveness was controlled. However, parenting dissimilarity may be more likely to affect marital conflict for parents of ADHD children because they are given more opportunity to have conflict about their children's problems and because their elevated levels of parenting stress (Breen \& Barkley, 1988) 
may make it more difficult to negotiate effectively and resolve differences. Parenting similarity may also affect parenting alliance. Parenting alliance, a concept proposed by Weissman and Cohen (1985), refers to the degree of commitment and cooperation between a mother and father in child rearing and has been associated with parenting style, parenting well-being, and marital satisfaction (Abidin \& Brunner, 1995). Research from social psychology suggests that attitudinal similarity predicts cohesion in groups (Terborg, Castore, \& DeNinno, 1976). Having similar parenting approaches may therefore be a key determinant of developing a good parenting alliance. To compare the results of this study with previous studies this study also examined the relation between parenting similarity and a global measure of marital adjustment.

Parenting similarity may also affect parents' own well-being in their parenting roles, including parenting stress, satisfaction, and selfefficacy. These three interrelated constructs (Mouton \& Tuma, 1988) are associated with children's mental health (Johnston \& Mash, 1989). Mothers of ADHD children report greater parenting stress (Breen \& Barkley, 1988) and lower satisfaction and self-efficacy (Mash \& Johnston, 1983) than mothers of normal children. Among children with ADHD, parenting stress has been associated with disruptive behavior problems (Anastopoulos, Guevremont, Shelton, \& DuPaul, 1992). There are several reasons why parenting similarity might affect parenting well-being. First, effects of parenting similarity on marital functioning may spill over to parenting well-being. For example, marital conflict arising from parenting dissimilarity might leave parents with fewer emotional resources to cope with stressors presented by their children. In fact, marital quality has been linked to parenting stress (Lavee, Sharlin, \& Katz, 1996). Second, parents with dissimilar parenting approaches may exhibit more unsupportive and less supportive co-parenting behavior toward one another. Unsupportive coparenting behavior might make parents feel alone and overwhelmed by the challenges presented by their children, resulting in an increase in parenting stress. Unsupportive co-parenting may also lead parents to question their own parenting effectiveness and thereby decrease parenting self-esteem.

Understanding the role of parenting similarity in the behavior of ADHD children could have important implications for treatment of these children. Parent training is one of the recommended treatments 
for these children (Barkley, 1990). If parenting similarity influences ADHD children's behavior and family functioning, then it may be important to target this variable in parent training programs.

\section{METHOD}

\section{Participants}

Participants were drawn from a pool of referrals to an ADHD Clinic at the University of Massachusetts Medical Center. Eligibility criteria were that (1) the child met DSM-IIIR or DSM-IV criteria for ADHD (see procedure below), (2) both a mother- and father-figure lived with the child at the time of the study and for at least one year prior, and (3) the child was between ages 7 and 12. Seventy-two families participated. One family was excluded because the father did not speak English and was unable to complete the questionnaires. One family was excluded because of missing data on variables relevant to this study. Children (64 boys and 6 girls) ranged in age from 7 to 12 yrs $(M=9.32 \mathrm{yrs}, S D=$ 1.46), mothers ranged in age from 26 to $49(M=37.10 \mathrm{yrs}, S D=4.96)$, and fathers ranged in age from 28 to $51(M=39.13$ yrs, $S D=5.35)$. Twelve children met criteria for Oppositional Defiant Disorder (ODD; $17 \%$ ), and one child met criteria for Conduct Disorder (CD; 1\%). The average number of children in these families was 2.25. In five of the families, the father was a step-father; in three families, the target child was adopted. In the remaining families, both parents were biological parents of the target child. All but one family was Anglo-American. The mean family annual income was approximately $\$ 57,000$ and both mothers and fathers had a mean education level of 14 years.

\section{Diagnostic Procedures}

Children were diagnosed with ADHD by licensed psychologists, post-doctoral interns, or a pre-doctoral intern at a clinic that specializes in such assessments. Diagnoses, made if children met DSM-IIIR or DSM-IV criteria for ADHD, were based on multi-method assessments using the following measures.

Fifty-one of the families were interviewed using a psychiatric semistructured interview procedure, similar to one that was designed spe- 
cifically for use with ADHD populations (Barkley, 1990). This procedure covered ADHD symptoms as well as symptoms from other DSM-IIIR and DSM-IV diagnoses. The interview also covered the child's developmental, school, peer, and family history. Fifteen of the participants were interviewed using the Diagnostic Interview Schedule for Children-Revised (DISC-R; Shaffer et al., 1993) instead of the diagnostic portion of the semi-structured interview. Standardized rating scales collected from parents and teachers were used to assist in the diagnoses.

\section{Procedure}

Each couple's participation involved one session lasting approximately 2 hours. The experimenter initially met with the couple jointly to provide instructions for completing the questionnaires and to obtain demographic information. During the session, each parent completed the battery of questionnaires in separate rooms. In addition to completing the questionnaires for this study, participants also completed questionnaires for two other studies (Arnold, O'Leary, \& Edwards, 1997; Arnold, in press).

\section{Measures}

General child rearing effectiveness. General child rearing was measured using the Modified Child Rearing Practices Report (MCRPR), a 40-item self-report measure of child rearing values and practices. It has adequate reliability (Rickel \& Biasatti, 1982) and validity (Jones, Rickel, \& Smith, 1980) and contains two factors: Warmth and Restrictiveness. To calculate an effectiveness score, the procedure parallels that used by Deal et al. (1989) using the full-length version of the Child Rearing Practices Report (Block et al., 1981): parents' standardized restrictiveness scores were subtracted from their standardized warmth scores. Thus, high scores reflect more effective parenting and low scores less effective parenting.

Discipline effectiveness. Discipline was measured using the Parenting Scale, a 30-item self-report scale of discipline practices (Arnold, O'Leary, Wolff, \& Acker, 1993). This scale has demonstrated good reliability and validity in preschool populations (Arnold et al., 1993) as well as for school-aged ADHD children (Harvey, Danforth, 
McCusker, \& Eberhardt, 1999). A total discipline score was calculated for each parent, with high scores reflecting frequent use of dysfunctional discipline practices and low scores reflecting frequent use of good discipline practices.

General child rearing similarity. An index of general child rearing similarity was calculated by correlating each couple's responses to items on the MCRPR. Although previous studies using Q-sort parenting measures have used the intraclass correlation (ICC) to calculate agreement indices, the ICC is problematic given the Likert-scale format of the MCRPR. Unfortunately, the ICC is dependent on the distribution of the couples' responses to the MCRPR. Finn's $r$ (Finn, 1970) is an agreement index similar to the ICC that does not have this undesirable property and is recommended in cases in which the distribution of scores may not be normally distributed (Whitehurst, 1984). In this sample, the mean index was $.52(S D=.28)$.

Discipline similarity. An index of discipline similarity was calculated by correlating each couple's responses to items on the Parenting Scale using Finn's $r$. In this sample, the mean index was .76 $(S D=$ .13).

Children's comorbid problems. The Child Behavior Checklist (CBCL; Achenbach, 1991) was used to measure children's internalizing and disruptive behavior problems. The CBCL is a commonly used measure of child psychopathology which has adequate reliability and validity (Achenbach, 1991). The Externalizing factor, composed of two subscales measuring aggressive and delinquent behavior, is distinct from problems of inattention. ${ }^{1}$ The Internalizing factor consists of 3 subscales: Withdrawn, Somatic Complaints, and Anxious/Depressed. Mothers and fathers completed the CBCL independently; their externalizing scores correlated .63 and their internalizing scores correlated .56. Mothers' and fathers' scores on the CBC were aggregated because combining multiple methods of assessment has been shown to increase validity by decreasing measurement error (e.g., Schwarz, Barton-Henry, \& Pruzinsky, 1985).

Marital adjustment. The Dyadic Adjustment Scale (DAS) is a 32-item, widely used measure of marital adjustment that assesses four areas of marriage: dyadic cohesion, dyadic consensus, dyadic satisfaction, and affectional expression. It has been found to have good reliability and validity (Spanier, 1976).

Marital conflict. Marital conflict was assessed using the Adapted 
Conflict Tactics Scale (ACTS; Vivian \& Langhinrichsen-Rohling, 1994), which is a 28 -item scale that assesses the incidence of a variety of negative verbal and physical tactics the couple have used during disagreements over the past year. These tactics range from insulting and criticizing to threatening with a knife or gun. This scale is a modification of the Conflict Tactics Scale (Straus, 1979). Individuals indicated the frequency with which they and their spouses have used each tactic over the past year on a scale from 0 (never) to 6 (more than 20 ). Scores were calculated by summing these responses across the 28 items. Mothers' and fathers' reports correlated .46.

Parenting alliance. The Parenting Alliance Scale (PAI; Abidin, 1988) was used to measure the degree of commitment and cooperation between a mother and father in child rearing. This scale has adequate reliability and validity (Abidin \& Brunner, 1995). Mothers' and fathers' reports on the PAI correlated .45 .

Parenting stress. The Parenting Stress Index-Short Form (PSI-SF; Abidin, 1995) is a 36 item scale that measures parenting stress. It is designed to measure stress emanating from three domains: parents' personal distress, dysfunctional parent-child interactions, and child characteristics. Test-retest reliability for the scale is .84 and coefficient alpha is .91. This scale correlates .94 with the full-length version of the PSI, which has much support for its validity (for a review, see Abidin, 1995).

Parenting satisfaction and self-efficacy. The Parenting Sense of Competence scale (PSOC; Gibaud-Wallston, \& Wandersman, 1978 cited in Johnston \& Mash, 1989) is a 17-item scale that measures parenting satisfaction and self-efficacy. Each item is answered on a 6 point scale ranging from strongly agree (1) to strongly disagree (6). The scale has good internal consistency (.79) and predicts both internalizing and externalizing behavior in children (Johnston \& Mash, 1989).

\section{RESULTS}

Table 1 presents means and standard deviations for the main variables used in this study. First, the relationships between parenting similarity and each of the child and family variables were examined (Table 2). Both similarity indices are significantly related to children's disruptive behavior problems. Both indices are also associated with marital adjustment, marital conflict, and fathers' reports of parenting 
TABLE 1. Means and Standard Deviations of Main Variables

\begin{tabular}{lrrrr} 
& \multicolumn{2}{c}{ Mothers } & \multicolumn{2}{c}{ Fathers } \\
& M & SD & M & SD \\
Parenting Scale & 3.06 & .65 & 3.14 & .59 \\
Adapted Conflict Tactics Scale & 30.63 & 19.89 & 30.36 & 23.56 \\
Parenting Alliance Inventory & 79.32 & 12.14 & 84.51 & 10.22 \\
Parenting Stress Index & 88.79 & 18.05 & 84.85 & 10.22 \\
Parenting Sense of Competence Scale & 66.40 & 10.80 & 67.00 & 10.34 \\
CBCL Intemalizing Score & 55.16 & 10.95 & 54.21 & 12.16 \\
CBCL Extemalizing Score & 58.23 & 10.22 & 57.09 & 10.79 \\
\hline
\end{tabular}

Note. $\mathrm{CBCL}=$ Child Behavior Checklist

alliance. In addition, discipline similarity was associated with mothers' reports of parenting alliance, mothers' parenting stress, and fathers' parenting self-efficacy. Discipline similarity was associated with fathers' parenting stress at a probability level approaching significance.

Regression analyses were then used to examine these relationships controlling for parenting effectiveness. For each dependent variable, two regression equations were created. In one, discipline similarity, mothers' discipline effectiveness, and fathers' discipline effectiveness were entered. In the second, general child rearing similarity, mothers' general child rearing effectiveness, and fathers' general child rearing effectiveness were entered. Results of these analyses are also reported in Table 2. Both parenting similarity indices remain significantly associated with children's disruptive behavior problems. Both indices also remain significantly related to general marital adjustment, mothers' reports of marital conflict, and fathers' reports of parenting alliance. General similarity, but not discipline similarity, remain significantly related to fathers' reports of marital conflict and discipline similarity remain significantly associated with mothers' parenting stress. The relationship between discipline similarity and mothers' reports of parenting alliance, fathers' reports of marital conflict, and fathers' parent- 
TABLE 2. Relation Between Parenting Similarity and Marital, Parenting, and Child Variables

\begin{tabular}{|c|c|c|c|c|}
\hline \multirow[b]{2}{*}{ Dependent Variable } & \multicolumn{2}{|c|}{ Discipline Similarity } & \multicolumn{2}{|c|}{ General Similarity } \\
\hline & $\begin{array}{l}\text { simple } \\
\text { correlation }\end{array}$ & $\begin{array}{l}\text { controlling for } \\
\text { parenting } \\
\text { effectiveness }\end{array}$ & $\begin{array}{l}\text { simple } \\
\text { correlation }\end{array}$ & $\begin{array}{l}\text { controlling for } \\
\text { parenting } \\
\text { effectiveness }\end{array}$ \\
\hline \multicolumn{5}{|l|}{ Child Functioning } \\
\hline Externalizing & $0.37^{\star *}$ & $.24^{*}$ & $.27^{\star}$ & $.23^{*}$ \\
\hline Internalizing & .11 & .06 & 0.05 & .02 \\
\hline \multicolumn{5}{|l|}{ Marital Functioning } \\
\hline \multicolumn{5}{|l|}{ Mother report } \\
\hline Marital adjustment & $.39^{\star * \star}$ & $.33^{\star *}$ & $.33^{\star *}$ & $.34^{\star *}$ \\
\hline Parenting alliance & $.28^{*}$ & .15 & .17 & .08 \\
\hline Marital conflict & $\square .38^{* \star *}$ & $\square .42^{* * *}$ & $0.22^{*}$ & $\square .35^{* *}$ \\
\hline \multicolumn{5}{|l|}{ Father report } \\
\hline Marital adjustment & $.54^{\star * *}$ & $.40^{\star * *}$ & $.57^{* \star *}$ & $.49^{* \star *}$ \\
\hline Parenting alliance & $.42^{\star \star \star}$ & $.26^{*}$ & $.44^{\star \star *}$ & $.25^{*}$ \\
\hline Marital conflict & $.26^{*}$ & 0.16 & $.32^{* *}$ & $.25^{*}$ \\
\hline \multirow{2}{*}{\multicolumn{5}{|c|}{$\begin{array}{l}\text { Parenting well-being } \\
\text { Mothers }\end{array}$}} \\
\hline & & & & \\
\hline Parenting stress & - $25^{*}$ & - $.24^{*}$ & ( .06 & ( .06 \\
\hline PSOC & .05 & .03 & $\square .11$ & .14 \\
\hline \multicolumn{5}{|l|}{ Fathers } \\
\hline Parenting stress & (19a & ( .09 & 0.10 & .21 \\
\hline PSOC & $.25^{*}$ & ( .02 & .16 & ( .20 \\
\hline
\end{tabular}

Note. PSOC = Parenting Sense of Competence Scale.

${ }^{* * *} p<.001,{ }^{* *} p<.01,{ }^{*} p<.05,{ }^{a} p<.10$

ing self-efficacy are no longer significant when parenting effectiveness was controlled.

\section{DISCUSSION}

General child rearing similarity and discipline similarity are significantly associated with fewer comorbid disruptive behavior problems among ADHD children, but were not associated with internalizing problems. Parenting similarity was also associated with higher marital adjustment and lower marital conflict among parents of ADHD children. Greater parenting similarity was also related to fathers' reports of greater parenting alliance. Finally, greater discipline similarity was associated with lower parenting stress for mothers. In contrast to previous studies in non-clinical populations (Deal et al., 1989; Sherrill, 1995), these effects are significant even controlling for parenting effectiveness. 
These results provide support for the important role that couples' similarity in child-rearing views and discipline practices may play for children with ADHD. ADHD children whose parents have dissimilar parenting approaches may be at risk for developing disruptive behavior problems. Thus, identifying and targeting parenting differences early on may help in preventing ADHD children from developing these more serious problems before they become entrenched. Addressing parenting similarity in parent training programs for ADHD children may help increase the effectiveness of such programs. Longitudinal research is needed to determine whether or not these parenting differences precede the onset of comorbid disruptive behavior problems.

A comparison of these results to studies of non-clinical samples using similar measures (Deal et al., 1989; Sherrill, 1995) suggests that this variable may play a more important role in families with children with ADHD than in non-ADHD families. This may be due to greater stress that ADHD children place on the family system (e.g., Breen \& Barkley, 1988; Mash \& Johnston, 1983); ADHD children may provide parents with more about which to disagree; or ADHD children may be more sensitive to interparental inconsistencies. Within-study comparisons are needed to replicate this finding, exploring possible reasons for differences between clinical and non-clinical samples.

The relation between parenting similarity and marital conflict stands in contrast to the findings of Deal et al. (1989), but is consistent with existing theory (Minuchin, 1985) and with Block et al.'s (1981) finding that parenting agreement is associated with less family discord. However, Block et al's finding regarding family discord may reflect parent-child conflict rather than marital conflict. Given the negative effects of marital conflict on children (Cummings \& Davies, 1994; Jouriles, Murphy, Farris, Smith, Richters, \& Waters, 1991; Snyder, Klein, Gdowski, Faulstich, \& LaCombe, 1988), the identification of parenting similarity as a risk factor for marital conflict among parents of ADHD children may have important treatment implications. This finding also suggests one possible reason why parents of ADHD children are more likely to divorce than parents of non-ADHD children (Barkley, Fischer, Edelbrock, \& Smallish, 1989).

Parenting similarity was related to fathers', but not mothers', perceptions of parenting alliance. It may be that there are gender differences in how parents appraise differences in child rearing approaches. 
It is also possible that mothers' and fathers' senses of parenting alliance are determined by different factors. This gender difference may also be caused by differences in parenting roles. Mothers tend to spend more time interacting with their children even when both parents are together (e.g., Arnold et al., 1997). Fathers, therefore, may have more opportunity to notice whether their wives are using different parenting practices from those that they themselves would use. Mothers may sometimes only be aware of child rearing differences if fathers verbalize their disagreement. Research is needed to examine both subjective and objective measures of parenting similarity and their relations to parenting alliance.

This is the first study to link parenting similarity and parenting alliance. One study has examined the relation between parenting similarity and co-parenting behavior, which should reflect the parenting alliance. In contrast to the results of the present study, Belsky, Crnic, and Gable (1995) found no link between child rearing similarity and observations of co-parenting behavior in parents of nonproblem twoyear-olds. The discrepancy may have been due to differences in the samples used in the two studies or to differences in the constructs and measures used. Further research is needed using multiple measures of parenting alliance in different samples to determine the cause of this discrepancy. Because parenting alliance is thought to be an important variable for success in family therapy (Weissman \& Cohen, 1985), identifying mechanisms for increasing parenting alliance could help to improve treatment for ADHD children. Targeting parents' similarity in child rearing and helping parents resolve differences may be one way of improving parenting alliance.

This is the first study to examine the relation between parenting similarity and parenting well-being. In this study, discipline similarity was related to mothers', but not fathers', parenting stress. This may also be caused by mothers' greater involvement in child care (Arnold et al., 1997). Lack of support and marital conflict that may arise from discipline similarity should be more likely to lead a parent to feel overwhelmed in the parenting role if the parent carries a larger share of parenting responsibilities. Research is needed to explore the mechanisms by which discipline similarity leads to parenting stress in mothers.

Several characteristics of this study suggest that these results should be interpreted with caution and argue for replication. The correlational and cross-sectional design of this study limits causal conclusions. For 
example, it may be that maritally satisfied parents are more likely to change their parenting practices and beliefs to be more similar to those of their spouses. In addition, this study relied on self-report of parenting and parent-report of child behavior, which may be biased. However, the effect of method variance on relations involving these variables should be minimized by two factors. First, the parenting variable used in this study is an index created by correlating mothers' and fathers' self-reports of their parenting. Couples' reporting biases would have had to be correlated with parenting similarity in order for them to affect results; for example, couples with dissimilar parenting approaches would have had to have a more problem-oriented responseset for method variance to account for these results. Second, mothers and fathers provided independent reports of child behavior and their scores were aggregated. This should have decreased bias in the assessment of child behavior. A final limitation of this study is the homogeneity of the sample in terms of SES and ethnicity. Research with more diverse clinical samples is needed.

Nonetheless, this study begins to illuminate how parenting similarity may affect both children with ADHD and their families. Research on families with ADHD children has primarily focused on dyadic relationships and individual rather than relational variables; these results point to the need to study the family systems of ADHD children in order to create a more sophisticated understanding of factors that contribute to or prevent the development of comorbid difficulties.

\section{NOTE}

1. The term externalizing problems is commonly used to refer both to disruptive behavior problems and to ADHD characteristics (e.g., McMahon, 1994). However, because the CBCL Externalizing factor includes only disruptive behavior problems and not ADHD symptoms, some individuals use externalizing problems to refer only to disruptive behavior problems. To avoid confusion, I will call the variable measured by the Externalizing factor of the CBCL disruptive behavior problems.

\section{REFERENCES}

Abidin, R. R. (1988). Parenting Alliance Inventory. Unpublished scale, University of Virginia, Charlottesville.

Abidin, R. R. (1995). Parenting Stress Index Short Form Test Manual. Charlottesville, VA: Pediatric Psychology Press. 
Abidin, R. R., \& Brunner, J. F. (1995). Development of a Parenting Alliance Inventory. Journal of Clinical Child Psychology, 24, 31-40.

Achenbach, T. M. (1991). Manual for the Child Behavior Checklist/4-18 and 1991 Profile. Burlington, VT: University of Vermont Department of Psychiatry.

American Psychiatric Association (1994). Diagnostic and statistical manual of mental disorders (4th ed.). Washington, DC: author.

Anastopoulos, A. D., Guevremont, D. C., Shelton, T. L., \& DuPaul, G. J. (1992). Parenting stress among families of children with Attention Deficit Hyperactivity Disorder. Journal of Abnormal Child Psychology, 20, 503-20.

Arnold, D. S., O'Leary, S. G., Wolff, L. S., \& Acker, M. M. (1993). The Parenting Scale: A measure of dysfunctional parenting in discipline situations. Psychological Assessment, 5, 137-144.

Arnold. E. H. (in press). Parental employment and conduct problems among children with Attention-Deficit/Hyperactivity Disorder: An examination of child care workload and parenting well-being as mediating variables. Journal of Social and Clinical Psychology.

Arnold, E. H., O'Leary, S. G., \& Edwards, G. H. (1997). Father involvement and self-reported parenting of children with ADHD. Journal of Consulting and Clinical Psychology, 65, 337-342.

Barkley, R. A. (1990). Attention-deficit hyperactivity disorder: A handbook for diagnosis and treatment. New York: Guilford Press.

Barkley, R. A. (1997). Behavioral inhibition, sustained attention, and executive functions: Constructing a unifying theory of ADHD, Psychological Bulletin, 121, 65-94.

Barkley, R. A., DuPaul, G. J., \& McMurray, M. B. (1990). Comprehensive evaluation of attention deficit disorder with and without hyperactivity as defined by research criteria. Journal of Consulting and Clinical Psychology, 58, 775-789.

Barkley, R. A., Fischer, M., Edelbrock, C. S., \& Smallish, L. (1989). The adolescent outcome of hyperactive children diagnosed by research criteria: I. An 8-year prospective follow-up study, Journal of the American Academy of Child and Adolescent Psychiatry, 29, 546-557.

Belsky, J., Crnic, K., \& Gable, S. (1995). The determinants of co-parenting in families with toddler boys: Spousal differences and daily hassles. Child Development, 66, 629-642.

Block, J. H., Block, J., \& Morrison, A. (1981). Parental agreement-disagreement on child-rearing orientations and gender-related personality correlates in children. Child Development, 52, 963-974.

Breen, M. J., \& Barkley, R. A. (1983). The Personality Inventory for Children: Its clinical utility with hyperactive children. Journal of Pediatric Psychology, 8, 359-366.

Breen, M. J., \& Barkley, R. A. (1988). Child psychopathology and parenting stress in girls and boys having attention deficit disorder with hyperactivity. Journal of Pediatric Psychology, 13, 265-280.

Cummings, E. M., \& Davies, P. (1994). Children and marital conflict: The impact of family dispute and resolution. New York: The Guilford Press.

Cunningham, C. E., \& Barkley, R. A. (1979). The interactions of hyperactive and 
normal children with their mothers during free play and structured task. Child Development, 50, 217-224.

Deal, J. E., Halverson, C. F., \& Wampler, K. S. (1989). Parental agreement on child-rearing orientations: Relations to parental, marital, family, and child characteristics. Child Development, 60, 1025-1034.

Finn, R. H. (1970). A note on estimating the reliability of categorical data. Educational and Psychological Measurement, 30, 71-76.

Gibaud-Wallston, J., \& Wandersman, L. P. (1978, August). Development and utility of the Parenting Sense of Competence Scale. Paper presented at the Annual Convention of the American Psychological Association, Toronto.

Harvey, E. A., Danforth, J. S., McCusker, W. R., \& Eberhardt, T. L. (1999). Validity of the Parenting Scale for children with attention-deficit/hyperactivity disorder. Manuscript submitted for publication.

Johnston, C. (1996). Parent characteristics and parent-child interactions in families of nonproblem children and ADHD children with higher and lower levels of oppositional-defiant behavior. Journal of Abnormal Child Psychology, 24, 85-104.

Johnston, C., \& Mash, E. J. (1989). A measure of parenting satisfaction and efficacy. Journal of Clinical Child Psychology, 18, 167-175.

Jones, D. C., Rickel, A. U., \& Smith, R. L. (1980). Maternal child-rearing practices and social problem-solving strategies among preschoolers. Developmental Psychology, 16, 241-242.

Jouriles, E. N., Murphy, C. M., Farris, A. M., Smith, D. A., Richters, J. E., \& Waters, E. (1991). Marital adjustment, parental disagreement about child rearing, and behavior problems in boys: Increasing the specificity of the marital assessment. Child Development, 62, 1424-1433.

Lavee, Y., Sharlin, S., \& Katz, R. (1996). The effect of parenting stress on marital quality: An integrated mother-father model. Journal of Family Issues, 17, 114-135.

Kendziora, K. T., \& O’Leary, S. G. (1993). Dysfunctional parenting as a focus for prevention and treatment of child behavior problems. In T. H. Ollendick \& R. J. Prinz (Eds.), Advances in Clinical Child Psychology, Vol. 15. (pp. 175-206). New York: Plenum Press.

Mash, E. J., \& Johnston, C. (1982). A comparison of the mother-child interactions of younger and older hyperactive and normal children. Child Development, 53, 1371-1381.

Mash, E. J., \& Johnston, C. (1983). Parental perceptions of child behavior problems, parenting self-esteem, and mothers' reported stress in younger and older hyperactive and normal children. Journal of Consulting and Clinical Psychology, 51, 68-99.

McMahon, R. J. (1994). Diagnosis, assessment, and treatment of externalizing problems in children: The role of longitudinal data. Journal of Consulting and Clinical Psychology, 5, 901-917.

Minuchin, P. (1985). Families and individual development: Provocations from the field of family therapy. Child Development, 56, 289-302.

Mouton, P. Y., \& Tuma, J. M. (1988). Stress, locus of control, and role satisfaction in clinic and control mothers. Journal of Clinical Child Psychology, 17, 217-224. 
Rickel, A. U., \& Biasatti, L. L. (1982). Modification of the Block Child Rearing Practices Report. Journal of Clinical Psychology, 38, 129-134.

Schwarz, J. C., Barton-Henry, M. L., \& Pruzinsky, T. (1985). Assessing child-rearing behaviors: A comparison of ratings made by mother, father, child, and sibling on the CRPBI. Child Development, 56, 462-479.

Shaffer, D., Schwab-Stone, M., Fisher, P. W., Cohen, P., Piacentini, J., Davies, M., Conners, C., \& Regier, D. (1993). The Diagnostic Interview Schedule for Children-Revised version (DISC-R): I. Preparation, field testing, interrater reliability, and acceptability. Journal of the American Academy of Child and Adolescent Psychiatry, 32, 643-650.

Sherrill, J. T. (1995). Inter-parental inconsistency and child behavior problems. Unpublished dissertation.

Snyder, D. K., Klein, M. A., Gdowski, C. L., Faulstich, C., \& LaCombe, J. (1988). Generalized dysfunction in clinic and nonclinic families: A comparative analyses. Journal of Abnormal Child Psychology, 16, 97-109.

Spanier, G. B. (1976). Measuring dyadic adjustment: New scales for assessing the quality of marriage and similar dyads. Journal of Marriage and the Family, 38, $15-28$.

Straus, M. (1979). Measuring intrafamily conflict and violence: The Conflict Tactics Scale. Journal of the Marriage and the Family, 41, 75-88.

Terborg, J. R., Castore, C., \& DeNinno, J. A. (1976). A longitudinal field investigation of the impact of group composition on group performance and cohesion. Journal of Personality and Social Psychology, 34, 782-790.

Vivian, D., \& Langhinrichsen-Rohling, J. (1994). Are bi-directionally violent couples mutually victimized? A gender-sensitive comparison. Violence and Victims, 9, 107-124.

Weissman, S. H., \& Cohen, R. S. (1985). The parenting alliance and adolescence. Adolescent Psychiatry, 12, 24-45.

Whitehurst, G. J. (1984). Interrater agreement for journal manuscript reviews. American Psychologist, 39, 22-28.

RECEIVED: 06/27/99

REVISED: 09/01/99

ACCEPTED: 09/19/99 